\title{
Blood Glucose Regulation Using Closed- and Open-Loop Insulin Delivery Systems
}

\author{
II. Peripheral Primed Square Wave Infusions \\ C. K. Botz, E. B. Marliss ${ }^{1}$, and A. M. Albisser \\ Division of Biomedical Research, Department of Surgery, and Research Institute of The Hospital for Sick Children, \\ and ${ }^{1}$ Department of Medicine, University of Toronto, Toronto, Canada
}

\begin{abstract}
Summary. Glucose was infused into anaesthetized dogs before and after pancreatectomy. In the diabetics blood glucose was regulated first by closedloop and then by open-loop insulin delivery schemes. Insulin requirements for the latter were determined by resolving the former into a sequence of 3 different infusion rates: during the baseline and recovery periods, basal insulin was delivered at $0.37 \pm$ $0.02 \mathrm{mU} / \mathrm{kg} / \mathrm{min}$, while during the $60 \mathrm{~min}$ glucose infusion $(10 \mathrm{mg} / \mathrm{kg} / \mathrm{min})$ there was an $8 \mathrm{~min}$ infusion at $4.96 \pm 0.37 \mathrm{mU} / \mathrm{kg} / \mathrm{min}$ and a 52 min component at $1.85 \pm 0.08 \mathrm{mU} / \mathrm{kg} / \mathrm{min}$. With the open-loop method under these highly standardized conditions glycaemia was similar to normal controls but IRI levels were significantly higher, 13.5 vs $8.0 \mu \mathrm{U} / \mathrm{ml}$ $(\mathrm{p}<0.05)$ in the baseline and recovery periods and 74 vs $25 \mu \mathrm{U} / \mathrm{ml}(\mathrm{p}<0.05)$ during the glucose infusion. It was concluded that: constant normoglycaemia can be maintained in the basal state by a constant rate of peripheral insulin delivery but at rates resulting in peripheral hyperinsulinaemia; the glycaemic response to glucose infusion can be normalized by a two component waveform of insulin delivery; and the closed-loop method can serve as a useful guide in determining insulin requirements.
\end{abstract}

Key words: Blood glucose regulation and control, glucose infusion, continuous low dose peripheral insulin infusion, pancreatectomized dogs, artificial beta cell, hyperinsulinaemia.

Studies using presently available closed-loop insulin delivery systems as an artificial endocrine pancreas $[1,2]$ have a number of limitations. Usually they are restricted in duration to one or two days, partly because of the size of the device, but mainly because of the need for continuous blood withdrawal [3] for glucose sensing [4]. The glycaemic normalization achieved by these devices is frequently associated with peripheral hyperinsulinism [5-8] unless the insulin is delivered into the portal vein [9].

Because of these and other limitations several groups [7, 10-15] have described pre-programmed insulin delivery mechanisms. These open-loop devices do not depend on a glucose sensor and hence can be made portable enabling ambulant subjects to participate in studies lasting more than one or two days. Pre-programmed waveforms used included various diurnal combinations of a 'basal' insulin rate enhanced before or during the meal period either as one or more square waves $[7,10-12,15]$ or in a pattern intended to reproduce the normal peripheral insulin profile [13]. Our group [7] studied pancreatectomized dogs for 12 months and showed that fasting euglycaemia and normal postprandial glucose levels could be obtained using a prototype portable insulin delivery device [14].

Insulin requirements before, during and after a caloric challenge can readily be determined by the application of a closed-loop system $[5,16,17]$. The primary aim of the present study was to examine whether a closed-loop waveform could be resolved into three simple open-loop components: a constant basal rate which would maintain normoglycaemia in the pre- and post-challenge periods and a combination of only two elevated rates which would normalize the glycaemic response to a peripheral glucose infusion. A secondary aim was to compare to normal the resulting IRI levels when peripheral insulin was delivered with the closed- and open-loop methods. 


\section{Materials and Methods}

\section{Animal Preparation and Blood Sampling}

Six non-obese male Beagles, one to two years of age and weighing $11.3 \pm 0.8 \mathrm{~kg}$, were fasted for $12 \mathrm{~h}$ prior to each experiment. All were studied as controls but only five were included in the post pancreatectomy protocols. Dogs were fed a weight maintaining diet consisting of equal amounts of dog chow and canned food given once daily at $0900 \mathrm{~h}$. General anaesthesia was induced with a IV 1:1 mixture of pentobarbital (Nembutal Sodium Injection, Abbott Laboratories, N. Chicago, Ill.) and pentothal (Pentothal Sodium, Abbott Laboratories, Montreal, Quebec) $(25 \mathrm{mg} / \mathrm{kg}$ body weight). Anaesthesia was maintained throughout the experiment by a slow infusion $(25 \mathrm{mg} / \mathrm{h})$ of pentothal. A dual-lumen catheter (Abjad Industries, Mississauga, Ont.) was placed in each superficial jugular vein; one provided blood diluted $1: 1$ for continuous glucose monitoring and the other was arranged in such a way as to permit the withdrawal over short time intervals of essentially undiluted blood for the later determination of insulin. To compensate for blood lost during surgery and sampling $0.154 \mathrm{~mol} / \mathrm{l}$ saline was infused at a rate of $1-2 \mathrm{ml} / \mathrm{min}$ throughout the experiment. Heparinized whole blood from a jugular vein catheter was collected at $-40,-10,0,5,10,15,30,45,60,75,90,120,150$ and $180 \mathrm{~min}$ directly into $1 \frac{1}{2} \mathrm{ml}$ centrifuge tubes, the start of the glucose challenge being designated time 0 .

Blood was collected on ice and centrifuged with minimal delay at $4{ }^{\circ} \mathrm{C}$, and supernatants frozen at $-20^{\circ} \mathrm{C}$ until assay.

\section{Diabetes Induction and Management}

Diabetes was induced by surgical removal of the pancreas as previously described $[5,17]$. Subcutaneous injection of single doses of equal amounts of NPH and crystalline zinc porcine insulin formulations were given daily between experiments (Connaught Laboratories Ltd., Toronto, Ont.). The dose was based on fasting and $2 \mathrm{~h}$ postprandial blood glucose levels, determined 5 times weekly. Pancreatic enzyme supplementation (Cotazyme, Organon Ltd., Montreal, Quebec) was given with meals. All dogs maintained their presurgical weights $( \pm 1 \mathrm{~kg}$ ) with this treatment.

On the day prior to an experiment, the diabetic animals were given half the meal and half the dose of subcutaneous crystalline zinc insulin at 0900 and the remainder at $1700 \mathrm{~h}$. Meals not finished by $2000 \mathrm{~h}$ were removed so that in all cases on the morning of the experiment the animals were hyperglycaemic $(300-400 \mathrm{mg} / \mathrm{dl})$, suggesting that very little residual insulin was present; concurrent plasma IRI levels were less than $2 \mu \mathrm{U} / \mathrm{ml}$. Euglycaemia was restored over $1-3 \mathrm{~h}$ by a combination of continuous intravenous infusion and boluses of 0.5 to 1.0 units insulin, and maintained for at least $40 \mathrm{~min}$ prior to glucose challenge.

\section{Analytical Methods}

A continuous blood glucose analyzer [18] was calibrated against a Beckman Glucose Analyser (Beckman Instruments, Fullerton, Cal.) to read equivalent plasma glucose concentration as previously described. Its total time delay was $2 \mathrm{~min}$.

Plasma IRI was determined using an anti-porcine insulin antiserum (from Dr. Peter Wright, Minneapolis, Minn.), a dextrancoated charcoal separation of free from bound hormone, and a pork insulin standard (Novo Research Inst., Copenhagen, Denmark). Standard statistical methods were employed using the unpaired Student's $t$ test to examine the significance of the differences between the responses of normal and diabetic animals. [All data are reported as mean \pm SEM.]
Infused insulin was porcine neutral crystalline zinc insulin (Connaught Laboratories Ltd., Toronto, Ont.) diluted in $0.154 \mathrm{~mol} / 1$ saline to a concentration of $17 \mathrm{mU} / \mathrm{ml}$. The precision of the saline-insulin dilution was verified by immunoassay, as was the immunologic identity of the infused insulin and the standards in the assay conditions used (data not shown). Insulin infusion was with a pulsatile pump (Lambda Pump, Harvard Instruments Ltd., Millis, Mass.).

\section{Blood Glucose Control}

Glycaemic regulation in the diabetic dogs was realized first with closed-loop and then with open-loop methods, with an intervening interval of 7 to 28 days. The closed-loop method utilized the same continuous glucose analyzer as above in an artificial pancreas instrument $[5,17]$ in which the chosen algorithms [19] and constants were as defined in Appendix 1. Insulin was infused into a saphenous vein. With the closed-loop method the rate of insulin delivery responded on a minute-by-minute basis to both the blood glucose level and its rate of change.

With the open-loop method, the same pump was used and the rate of insulin delivery was fixed in a predetermined waveform with only 3 components. The selection of amplitudes and durations of these rates is described below.

\section{Glucose Infusions}

Glucose infusions consisted of a 60 min peripheral IV infusion into the contralateral saphenous vein at a rate of $10 \mathrm{mg} / \mathrm{kg} / \mathrm{min}$. All challenges started after a $40 \mathrm{~min}$ constant baseline period and were followed by a $120 \mathrm{~min}$ recovery period.

\section{Waveform Determination for the Open-Loop Method}

For each dog the rates of insulin delivery by the open-loop method were chosen to approximate the waveform obtained previously with the closed-loop method. Thus, during the baseline and recovery periods a constant basal rate of insulin was infused equal to the mean of that which was infused over the same periods using the closed-loop method. During the challenge period an initial high rate and a subsequent lower rate of insulin delivery were used, the former for 8 minutes and the latter for 52 minutes. The high rate was chosen on the basis of the maximum initial rate attained with the closed-loop method, while the lower rate was computed so that the total amount of insulin infused over the challenge was the same for both methods.

\section{Results}

\section{Normal Controls (Figs. 1 and 2)}

During glucose infusion blood glucose concentrations rose from baseline values of $98 \pm 2$ to peak values of $173 \pm 7 \mathrm{mg} / \mathrm{dl}$. When the infusion was terminated it dropped in $40 \mathrm{~min}$ to levels of $87 \pm 2 \mathrm{mg} / \mathrm{dl}$. The peripheral IRI concentrations were stable at $8 \pm$ $1 \mu \mathrm{U} / \mathrm{ml}$ during the $40 \mathrm{~min}$ baseline period and rose 3 fold during glucose infusion. Post-infusion IRI concentrations returned within $15 \mathrm{~min}$ to baseline values 

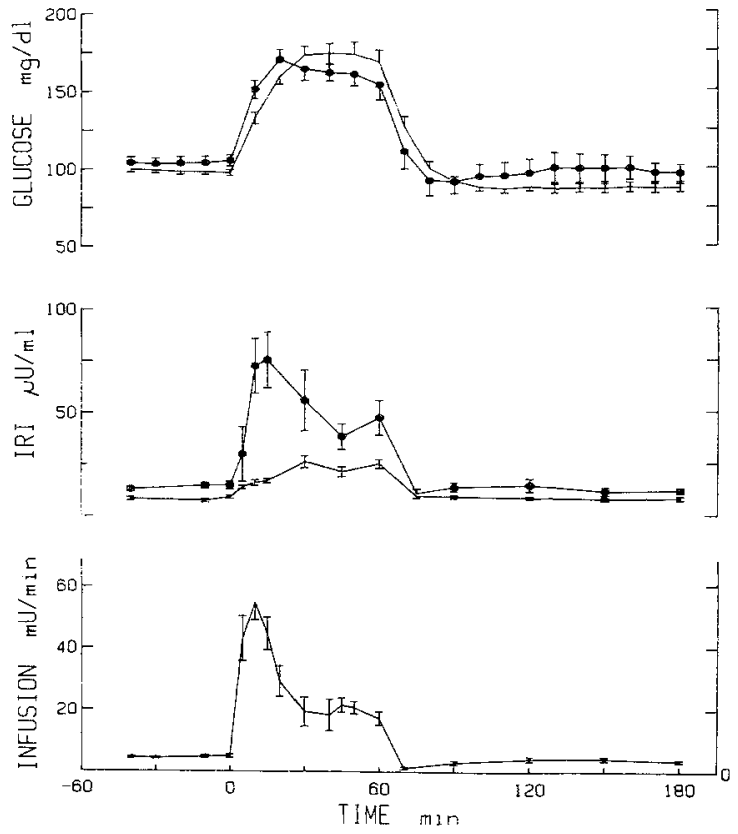

Fig. 1. Glucose regulation before, during and after a peripheral glucose infusion of $10 \mathrm{mg} / \mathrm{kg} / \mathrm{min}$ from 0 to $60 \mathrm{~min}$. Normal controls $(n=16)$ and diabetic dogs $(n=5$, closed circles) treated with a closed-loop insulin delivery system. Upper panel: glucose concentration - Centre panel: peripheral plasma insulin concentration - Lower panel: peripheral insulin infusion rates (diabetic dogs only)

and remained constant throughout the recovery period.

A total of 16 infusions were administered to the six normal dogs. Repeated studies under identical experimental conditions, either on the same day or weeks later, verified the reproducibility of the response of each dog. For example, one dog $(12.8 \mathrm{~kg})$ was studied 3 times, twice on one day and then again $30 \mathrm{~d}$ later. With the first infusion blood glucose rose from baseline values of 103 to a peak value of $173 \mathrm{mg} / \mathrm{dl}$ while insulin levels rose from 12 to a peak of $23 \mu \mathrm{U} / \mathrm{ml}$. With the second infusion the corresponding values were from 91 to $169 \mathrm{mg} / \mathrm{dl}$ and from 11 to $25 \mu \mathrm{U} / \mathrm{ml}$. Thirty days later the corresponding values were from 96 to $165 \mathrm{mg} / \mathrm{dl}$ and from 6 to $25 \mu \mathrm{U} / \mathrm{ml}$.

\section{Diabetic Dogs: Closed-Loop Insulin Infusion}

(Fig. 1)

During the baseline period the blood glucose concentration was $104 \pm 4 \mathrm{mg} / \mathrm{dl}$ and rose in $20 \mathrm{~min}$ to a peak of $170 \pm 7 \mathrm{mg} / \mathrm{dl}$ but declined during the final 40 minutes of the glucose infusion to $153 \pm 10 \mathrm{mg} /$ dl. Blood glucose then dropped rapidly to baseline levels and remained in this range throughout the recovery period.
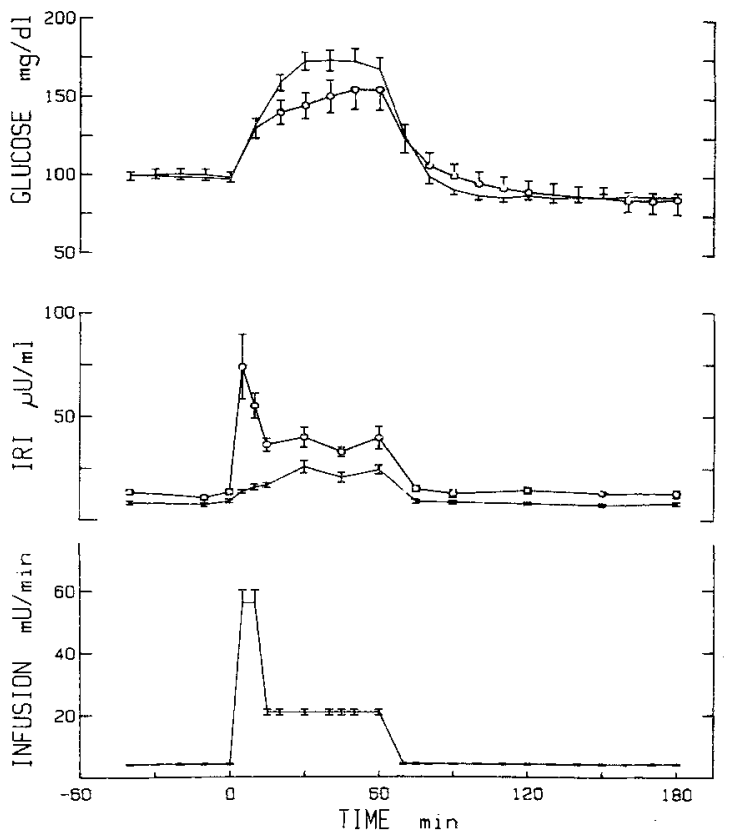

Fig. 2. Glucose regulation before, during and after a peripheral glucose infusion of $10 \mathrm{mg} / \mathrm{kg} / \mathrm{min}$ from 0 to $60 \mathrm{~min}$. Normal controls (as in Fig. 1) and diabetic dogs ( $\mathbf{n}=7$, open circles) treated with an open-loop insulin delivery system. Upper panel: blood glucose concentration - Centre panel: plasma insulin concentration - Lower panel: peripheral insulin infusion rates (diabetic dogs only)

Peripheral IRI levels in the baseline period were $15 \pm 1 \mu \mathrm{U} / \mathrm{ml}$, rose $5-6$ fold 15 minutes from the start of the challenge, and declined gradually thereafter until the infusion was terminated.

In the baseline period the mean insulin infusion rate was $4.2 \pm 0.5 \mathrm{mU} / \mathrm{min}$. During the glucose infusion the peak insulin infusion of $55 \pm 6 \mathrm{mU} / \mathrm{min}$ occurred at 10 minutes, the rate declining rapidly by 30 minutes but remained elevated at $20 \pm 2 \mathrm{mU} /$ min. In the recovery period the insulin infusion declined rapidly to baseline values. The total amounts of insulin administered over the baseline, glucose infusion and recovery periods respectively were $169 \pm 9,1534 \pm 64,506 \pm 26 \mathrm{mU}$.

\section{Diabetic Dogs: Open-Loop Insulin Infusion} (Fig. 2)

During the baseline period, the blood glucose concentration was $100 \pm 4 \mathrm{mg} / \mathrm{dl}$, the basal insulin infusion rate was $4.2 \pm 0.2 \mathrm{mU} / \mathrm{min}$ and the peripheral IRI levels were $14 \pm 1 \mu \mathrm{U} / \mathrm{ml}$. Glucose levels rose to a peak of $155 \pm 13 \mathrm{mg} / \mathrm{dl}$ during the infusion and fell to preinfusion levels within 20 min after the termination of the glucose infusion. Peripheral plasma IRI levels rose to a peak of $74 \pm 16 \mu \mathrm{U} / \mathrm{ml}$ in $5 \mathrm{~min}$ and then declined to a plateau of $40 \pm 5 \mu \mathrm{U} / \mathrm{ml}$ during 
the remainder of the glucose infusion. In the recovery period IRI levels returned to steady baseline values in approximately 15 minutes.

The insulin infusion rate in both the baseline and recovery periods was constant at $4.2 \pm 0.2 \mathrm{mU} / \mathrm{min}$. During the glucose infusion the waveform included an initial high rate of $56 \pm 4 \mathrm{mU} / \mathrm{min}$ for 8 minutes and then a rate of $21 \pm 1 \mathrm{mU} / \mathrm{min}$ for $52 \mathrm{~min}$. Total amounts of insulin infused during the baseline, glucose infusion and recovery periods were respectively $183 \pm 14,1620 \pm 165$, and $466 \pm 62 \mathrm{mU}$.

\section{Diabetics versus Controls}

Data in Figure 1 compare the normal controls and the diabetics treated with the closed-loop system. Glycaemia differed significantly $(\mathrm{p}<0.015)$ from controls only at 10 minutes when it was higher by $20 \mathrm{mg} / \mathrm{dl}$. Peripheral IRI levels were significantly higher than controls at all times. At 75 minutes these differences were not significant $(p>0.05)$.

With the open-loop method of treatment (Fig. 2) glycaemia differed from controls only at 30 minutes when it was $28 \mathrm{mg} / \mathrm{dl}$ lower. Peripheral IRI levels were significantly higher than controls at all times except at 75 minutes when these differences were not significant. During the course of the experiment, the insulin infusion rates (Fig. 2) differed only at times 1 , 10 and 15 minutes; however, the same total amounts of insulin were infused in the baseline, challenge and recovery periods.

\section{Discussion}

Closed-loop systems normalize glycaemia and provide information of the minute-by-minute insulin requirements for a variety of caloric challenges. This information has been useful in determining and adjusting subcutaneous insulin requirements [20]. In this report we demonstrate that it can be used in programming open-loop insulin delivery devices. To this end, the insulin requirements to a glucose infusion were determined in dogs using the closed-loop method. After each experiment the resulting insulin infusion pattern was abstracted into a 3-component waveform for use in subsequent open-loop studies on the same dog. For the group this procedure resulted in an insulin infusion waveform which was remarkably comparable for both methods (Figs. 1 and 2, lower panels) and equal amounts of insulin were infused during the glucose infusion and of course during the baseline and recovery periods when the basal rate for the open-loop method is easily chosen from the closed-loop data.

In the open-loop study, the initial high rate of insulin delivery coincided with the start of the glucose infusion. The combination of the high rate of insulin delivery and the lack of delay in its initiation resulted in a clear attenuation of the glycaemic rise with the open-loop waveform. Glycaemia was thus significantly $(\mathrm{p}<0.05)$ lower than controls at $20 \mathrm{~min}$ (Fig. 2, upper panel), the difference disappearing by the end of the challenge. IRI levels in the diabetics (Figs. 1 and 2) were significantly higher than controls at all times. Thus glycaemic normalization in anaesthetized dogs is accompanied by peripheral hyperinsulinism when the insulin is infused peripherally. This does not occur under similar experimental conditions when insulin is delivered portally [9] although it has been reported following pancreatic islet transplantation in the peritoneum of diabetic rats [21]. The results presented here support the contention [22] that minimizing the delay of the closed-loop system probably reduces the required amount of early insulin. In the present study the closed-loop instrument had a delay of 2 minutes and included parameters (Appendix 1) which accelerated insulin delivery some 11 fold with rising glycaemia (Fig. 1). Perhaps a greater than necessary amount of insulin was given with the similar but earlier high infusion rate of the open-loop study because it was applied without delay. Resulting glycaemic levels were lower than normal as shown in Figure 2.

In these studies the 60 minute glucose infusion at a rate of $10 \mathrm{mg} / \mathrm{kg} / \mathrm{min}$ into a peripheral vein was chosen because it is a defined caloric challenge which resulted in reproducable glucose and insulin responses in the anaesthetized dog. We have observed no differences in the responses of diabetic dogs when the glucose infusion was delivered portally $[5,9]$ or peripherally [17]. The latter route was used in this study to explore the adequacy of this route (the only one feasible in human studies at present), and to avoid the necessity of repeated laparotomy. This intravenous glucose infusion in pancreatectomized dogs produced a glycaemic response which previously could only be normalized by a closed-loop insulin delivery system specifically programmed to meet this challenge.

The major advantage of the open-loop system is its simplicity, applicability and the elimination of the need for a glucose sensor. Within the constraints of the present study, we conclude that preprogramming of open-loop waveforms can be guided by the results of closed-loop studies. Whether these findings can be extended to the heterogeneous situation of human diabetes mellitus remains to be established.

\footnotetext{
Acknowledgements. This work was conducted as a research project in the Artificial Pancreas Programme at The Hospital for Sick Children in Toronto, and benefited in part from the financial support of The Juvenile Diabetes Foundation, the Juvenile Diabetes Research Foundation, The Medical Research Council of Canada, The Pfizer Company of Canada, and an Ontario Ministry of
} 
Health Fellowship to one of the authors (CKB). The authors gratefully acknowledge the advice and criticism from Dr. B.S. Leibel and the helpful assistance received from Dr. W. Zingg and the staff of The Division of Surgical Research, Department of Surgery, at The Hospital for Sick Children. We thank Ms. Irene Gibson for her help in typing and preparing the manuscript.

\section{Appendix I}

The algorithms for the closed-loop control system are as follows: $R_{\mathrm{I}}=1 / 2 \mathbf{M}_{\mathrm{I}}\left[1+\tanh \mathrm{S}_{\mathrm{I}}\left(\mathrm{G}_{\mathrm{p}}-\mathrm{B}_{\mathrm{I}}\right)\right]$

$\mathrm{G}_{\mathrm{p}}=\mathrm{G}+\mathrm{DF}$

where,

$\mathrm{DF}=\mathrm{K}_{1}(\mathrm{~A})^{3}+\mathrm{K}_{2}(\mathrm{~A})$

$\mathrm{G}_{\mathrm{p}}$ is the 'projected' glycaemia in $\mathrm{mg} / \mathrm{dl}$

$\mathrm{G}$ is the measured glycaemia in $\mathrm{mg} / \mathrm{dl}$

$R_{I}$ is the rate of insulin delivery in $\mathrm{mU} / \mathrm{min}$

$\mathrm{M}_{\mathrm{I}}$ is the maximum rate of insulin delivery in $\mathrm{mU} / \mathrm{min}$

tanh is the hyperbolic tangent function which is defined

$\tanh (x)=[\exp (x)-\exp (-x)] /[\exp (x)+\exp (-x)]$

$\mathrm{S}_{\mathrm{I}}$ is the steepness parameter of the argument of the hyperbolic tangent function in $\mathrm{dl} / \mathrm{mg}$

$B_{I}$ is the position parameter in the argument of the tanh function in $\mathrm{mg} / \mathrm{dl}$ and corresponds to the glycaemia at which the halfmaximum insulin infusion rate occurs. Changing $B_{I}$ shifts the curve to the left or right without changing its shape.

$\mathrm{DF}$ is the difference factor in $\mathrm{mg} / \mathrm{dl}$ and depends on the rate of change of glycaemia

$\mathrm{K}_{1}$ is the scaling parameter for the cubic term in $\mathrm{DF}$

$\mathrm{K}_{2}$ is the scaling parameter of the linear term in DF

$\mathrm{A}$ is the linearly weighted mean time rate of change of glycaemia in $\mathrm{mg} / \mathrm{dl} / \mathrm{min}$ computed each minute on the basis of the present $\left(\mathrm{G}_{0}\right)$ and previous three $\left(\mathrm{G}_{-1}, \mathrm{G}_{-2}, \mathrm{G}_{-3}\right)$ measured glycaemias.

$A=\left(4 G_{0}-3 G_{-1}-2 G_{-2}+G_{-3}\right) / 10$

The following parameters were used throughout:

$\mathrm{M}_{1}=0.50 \mathrm{mU} / \mathrm{kg} / \mathrm{min}$

$\mathbf{K}_{1}=1(\mathrm{mg} / \mathrm{dl})^{-2}$

$\mathrm{S}_{1}=0.0175 \mathrm{dl} / \mathrm{mg}$

$\mathbf{K}_{2}=10(\mathrm{mg} / \mathrm{dl})$

$\mathrm{B}_{1}=175 \mathrm{mg} / \mathrm{dl}$

\section{References}

1. Albisser, A. M., Leibel, B.S.: The artificial pancreas. Clin. Endocrinol. Metab. 6, 457-479 (1977)

2. Santiago, J. V., Clemens, A. H., Clarke, W. L., Kipnis, D. M.: Closed-loop and open-loop devices for blood glucose control in normal and diabetic subjects. Diabetes 28, 71-81 (1979)

3. Gander, R. E., Albisser, A.M., Botz, C. K., Leibel, B.S., Zingg, W.: An all plastic double-lumen catheter for continuous blood sampling. Med. Instrum. 9, 187-188 (1975)

4. Albisser, A. M., Ellman, J., Hanna, A., Goriya, Y., Minuk, H.: Continuous blood glucose analysis in vitro and in vivo. Diabetologia 15, 303-308 (1978)

5. Botz, C. K., Albisser, A. M., Leibel, B. S., Zingg, W., Gander, R. E.: Comparison of peripheral and portal routes of insulin infusion by a computer-controlled insulin infusion system (artificial endocrine pancreas). Diabetes 25, 691-700 (1976)

6. Horwitz, D. L., Gonen, B., Zeidler, A., Langer, B., Rodman, D.: An "artificial beta cell" for control of diabetes: comparison of glucose and free insulin levels with those achieved by subcutaneous insulin. Diabetes 26 (Suppl. 1), 376 (1977)
7. Goriya, Y., Bahoric, A., Marliss, E. B., Zinman, B., Leibel, B. S., Albisser, A. M.: Glycemic regulation using a programmed insulin delivery device. III. Long term studies. Diabetes 28 (in press) (1979)

8. Zinman, B., Stokes, E. F., Albisser, A. M., Hanna, A. K., Minuk, H. L., Stein, A. N., Leibel, B. S., Marliss, E. B.: The metabolic response to glycemic control by the artificial pancreas in diabetic man. Metabolism (in press) (1979)

9. Albisser, A. M., Botz, C. K., Leibel, B. S.: Blood glucose regulation using an open-loop insulin delivery system in pancreatectomized dogs given glucose infusions. I. Portal square waves. Diabetologia 16, 129-133 (1979)

10. Slama, G., Hautecouverture, M., Assan, R., Tchobroutsky, G.: One to five days of continuous intravenous insulin infusion on seven diabetic patients. Diabetes 23, 732-738 (1974)

11. Service, J. F.: Normalization of plasma glucose of unstable diabetes: studies under ambulatory fed conditions with pumped intravenous insulin. J. Lab. Clin. Med. 91, 480-489 (1978)

12. Deckert, T., Lørup, B.: Regulation of brittle diabetics by a pre-planned insulin infusion programme. Diabetologia 12, 573-579 (1976)

13. Genuth, S., Martin, P.: Control of hyperglycemia in adult diabetics by pulsed insulin delivery. Diabetes 26, 571-581 (1977)

14. Albisser, A. M., Jackman, W. S., Ferguson, R., Bahoric, A., Goriya, Y.: A portable precision pumping system for chronic, programmed insulin infusion. Med. Prog. Technol. 5, 187-193 (1978)

15. Pickup, J. C., Keen, H., Parsons, J. A., Alberti, K. G. M. M.: Continuous subcutaneous insulin infusion: an approach to achieving normoglycaemia. Br. Med. J. 1978I, 214-217

16. Marliss, E. B., Murray, F. T., Stokes, E. F., Zinman, B., Nakhooda, A. F., Denoga, A., Leibel, B. S., Albisser, A. M.: Normalization of glycemia in diabetics during meals with insulin and glucagon delivery by the artifical pancreas. Diabetes 26, 663-672 (1977)

17. Albisser, A. M., Leibel, B.S., Ewart, T. G., Davidovac, Z., Botz, C. K., Zingg, W.: An artificial endocrine pancreas. Diabetes 23, 389-396 (1974)

18. Albisser, A. M., Leibel, B. S., Johnson, W., Denoga, A., Botz, C. K., Marliss, E. B.: An improved technique for the rapid continuous measurement of whole blood glucose, suitable for clinical application in an artificial endocrine pancreas. Med. Prog. Technol. 5, 141-148 (1977)

19. Botz, C. K.: An improved control algorithm for an artificial beta cell. IEEE Trans. Biomed. Eng. 23, 252-255 (1976)

20. Lambert, A. E., Buysschaert, M., Marchand, E., Pierard, M., Bojcik, S., Lambotte, L.: Determination of insulin requirements in brittle diabetic patients by the artificial pancreas. Diabetes 27, 825-833 (1978)

21. Weber. C. J., Hardy, M. A., Lerner, R. L., Felig, P., Reemtsma, K.: Hyperinsulinemia and hyperglucagonemia following pancreatic islet transplantation in diabetic rats. Diabetes 25, 944-948 (1976)

22. Chacra, A. R., Fujita, Y., Herron, A. L., Seltzer, H. S.: Uniphasic insulin-secretory response in the pancreatic vein of dogs after an enteric glucose load. Diabetes 27, 21-26 (1978)

Received: November 9, 1978

and in revised form: March 19, 1979

Dr. A. M. Albisser

Biomedical Research

The Hospital for Sick Children

555 University Avenue

Toronto M5G 1 X8

Canada 